\title{
The Exploration Based on Aging Society Living Space
}

\author{
Jin Guang $\mathrm{Hu}$ \\ engineering college of YanBian University, Yanji 133002, China; \\ jgh118@163.com
}

Keywords: aging, the elderly, pension that occupy the home, residential building, space design.

\begin{abstract}
People's average life span almost Continuously increase for reasons of the improvement of medical technology, growth of economic, emphasis on health, and so on. Our country has entered the aging society as early as 2000 , and over 65 elderly population will reach about $23.4 \%$ of the total population by 2050. Despite the massive crowds' health is better than ever before, their physical ability and psychological ability have been changed. Conversely, these changes caused by the problem entice us to think about the elderly and coordination of the living space. Above all, the designation of the often used space such as the living room, bedroom, bathroom, kitchen should meet the psychological and physiological needs in the elderly. But at present the elderly residential building design theoretical system has not been formed, thus there are still so many things that are needed to complete, which in turn requires architects design personalized and elaborately by processing further study of the psychological, physiological characteristics and needs of old people, as well as giving full consideration to the elderly living habits.
\end{abstract}

\section{Introduction}

1.1 The background and purpose of the research

Although modern building regards function as the starting point of design, the people-oriented space design is often ignored by people. People's average life span almost Continuously increase for reasons of the improvement of medical technology, growth of economic, emphasis on health, and so on. Our country has entered the aging society as early as 2000, and over 65 elderly population had reached more than 130 million by 2013, and over 65 elderly population will reach about $23.4 \%$ of the total population by 2050. Despite the massive crowds' health is better than ever before, their physical ability and psychological ability have been changed. It is common among the old people in perception, and cognitive decline, in the physiological and psychological changes, and in the lower limbs flexibility, which entices us to think more about the elderly and coordination of the living space. In the principles of United Nations care for the elderly, Congress also acknowledges the elderly living conditions and its importance, and turns it on and through the five content relating to the elderly living conditions, including independence, participation, supervision, self-sufficient and personal dignity. Combining with china 's reality, the State Council Issues the "twelfth five-year" plan about the development of Chinese aging. The program puts forward clearly , during the "twelfth five-year" period, in our country "general establish the social endowment service system which fits with the population aging process, which keeps in harmony with the Economic and social development level, which Bases on the family and the community, which is Supported by institutions, making the elderly able to enjoy in old age well, so as to share the achievements of economic and social development."' That is to say that occupy the home endowment is the most basic way of pension in our country. Unfortunately, driven by the interests of the economy, most typical residential buildings are designed for the young, while these projects ignore the needs of the elderly. Therefore, the purpose of this study is to put forward consulting opinions for living space design by analyzing the characteristics and needs of the elderly. 
Table 1 The 65 - year - old population and its proportion

\begin{tabular}{lcccccccccc}
\hline \multicolumn{1}{c}{ Year } & 2004 & 2005 & 2006 & 2007 & 2008 & 2009 & 2010 & 2011 & 2012 & 2013 \\
\hline $\begin{array}{l}\text { population } \\
\text { /ten thousand } \\
\text { people }\end{array}$ & 9857 & 10055 & 10419 & 10636 & 10956 & 11307 & 11894 & 12288 & 12714 & 13161 \\
$\begin{array}{l}\text { Elderly } \\
\text { population } \\
\text { proportion }\end{array}$ & 7.6 & 7.7 & 7.9 & 8.1 & 8.3 & 8.5 & 8.9 & 9.1 & 9.4 & 9.7 \\
\hline
\end{tabular}

Table 2 The 65 - year - old population and predict by the proportion

\begin{tabular}{lcccccccccc}
\hline \multicolumn{1}{c}{ Year } & 2041 & 2042 & 2043 & 2044 & 2045 & 2046 & 2047 & 2048 & 2049 & 2050 \\
\hline $\begin{array}{l}\text { population } \\
\text { /ten thousand } \\
\text { people }\end{array}$ & 29609 & 30503 & 31425 & 32374 & 33351 & 34359 & 35396 & 36465 & 37565 & 38701 \\
$\begin{array}{l}\text { Elderly } \\
\text { population } \\
\text { proportion }\end{array}$ & 7.6 & 7.7 & 7.9 & 8.1 & 8.3 & 8.5 & 8.9 & 9.1 & 9.4 & 9.7 \\
\hline
\end{tabular}

\section{2 research method}

By collecting and studying the relevant data and documents, I study further the idea to be the theoretical basis of this study, and analysis the relationship between the elderly and architecture to sum up the valuable point of view. At last, I apply the viewpoint and method in the study of the elderly living space combing With Practical Experience。

\section{The characteristics and needs of old people}

\subsection{The physiological characteristics of the elderly}

With the growth of the age, body's aging becomes faster. First, it appears in terms of appearance. As the Loss of calcium in the bone, the body gradually becomes short and curves spine signs, etc, At the same time easy to fracture as the bone becomes crisp. Due to the atrophy of the metabolic function, Cell pigmentation, white and thin hair, dry and rough skin, wrinkled, fading elastic are access to body. Secondly, in terms of the declining perception, Such as sight, hearing, taste, smell, and touch, and so on, obviously the recession of visual auditory. Audiovisual is the main channel to get all sorts of information from the surroundings, so the old audiovisual recession is one of the main factors affecting their normal life. Finally athletic ability fading, A person's muscle strength peaked when he (she) is $20 \sim 30$ years old, and then begin to reduce. When he (she) is 70 years or so, the muscle strength will reduce about half. On the other hand, the decrease of brain cells also contributes to the slow of the old, which results in the decrease of the body flexibility and muscle strength, making them faltering and action inconvenience.

2.2 The psychological characteristics of the elderly

The change of the body causes a certain influence on psychological activities in the elderly, and their range of social shift from the society to the family because of the retirement. This kind of social change of the role prompts them to change their way of life, which makes them have the feeling of emptiness and aging. The feeling mainly displays in the more sensitive psychological, leading them easily feel lonely and loss, inferiority complex and depression. The old people will obviously lose confidence, and would rather choose compromise or even withdraw on the surrounding things. Maintain this state, and the range of old people will be more narrow, and they will be more difficult to adapt to the environment 。

2.3 The demand of the elderly

Architectural design concept is to satisfy the building function, and meet the needs of residents at the same time. Elderly residential buildings are designed according to the physiological and 
psychological characteristics of the elderly to meet the needs of them, such as safety needs, belonging needs, comfort demand, and social demand. Each space design in the elderly s living should pay attention to these characteristics and requirements of old people.

\section{Current status and development foreground of the aged housings construction}

For a long time, Undertaking development and progress, our country has made remarkable achievements, but further accelerate the speed of population aging process. From 2004 to 2004, more than the country's 65 - year - old increased from 098 million to 131 million, an average annual increase of more than 360; Over 65 elderly population increased from $7.6 \%$ to $9.7 \%$, an average annual increase of $0.23 \%$. Population aging process keeps company with the phenomenon of family miniaturization and empty-nested, and Intertwines with economic and social transformation of contradiction, Social endowment security and endowment service needs will increase sharply. Therefore, the State Council Issues the "twelfth five-year" plan about the development of Chinese aging. The program puts forward clearly, during the "twelfth five-year" period, in our country

"general establish the social endowment service system which fits with the population aging process, which keeps in harmony with the Economic and social development level, which Bases on the family and the community, which is Supported by institutions, making the elderly able to enjoy in old age well, so as to share the achievements of economic and social development.' That is to say that occupy the home endowment is the most basic way of pension in our country.

\section{The space design of the aged housings construction}

4.1 The space design principle of the aged housings construction

1) Take care of the physical principles: Because of physical declination, the elderly are inconvenient in walking, hiking, sitting and such daily living life. Therefore it's important to deepen the link among each activity space.

2) Take care of intelligence principles: With the increase of age, the intelligence of the old people is in varying degrees of decline. So it's necessary to leave enough room for maneuver in activity space.

3) Take care of the of vision and hearing principles: Giddiness and deafness are inevitable physiological phenomenon after people go into old age. So we should take account light, color, sound and various factors when designing houses for the elderly 。

4) Take care of the disabled principles: Part of the elderly need to use mechanical equipment in their life for multifarious reasons. So we should take account the passage width of the equipment when designing houses for the elderly.

4.2 Residential building space design that is suitable for the elderly

4.2.1 Living room

As the growth of the age, the old people shift the communication range from the society to their family, among which the vast majority of activities are completed in the living room, the main space of receive visitors, entertainment and family reunion. So we should take account the psychological and physiological needs of old people when designing houses for the elderly.

1. Good natural lighting

Living room is the major activity space in daily life for the elderly. Because of vision, the elderly demand $2 \sim 3$ times illumination higher than the young. So good natural lighting is the basic requirement of the quality for life, and is good for the old people's physical and mental health. Doubtlessly, we should take account the a good toward for the living rooms when designing houses for the elderly.

2. Reasonable space scale 
Reasonable space scale, namely the studio and the size of the deep is the need to meet with the life of the elderly life. In addition to the consideration of the commonly used furniture decorate, living room also need to meet the psychological and physiological needs of old people. On the one hand, too large a scale will affect the communication with relatives and friends, on the other hand, if the scale is too small, the activity of the elderly will be affected, especially for the disabled or the one who use a wheelchair. So the reasonable width size of their living room is $3300 \sim 4500 \mathrm{~mm}$, width and depth of the proportion should be 1:1 to 1:1. 2 .

3. Complete function of the space

As the public space of residential building, receiving visitors, entertaining and family reuniting, the living room Should maintain the integrity of its function space and independence. In order to improve the efficiency of the living room, when combining with bedroom, dining-room, kitchen and other living space, traffic streamline should not go through the living room.

\subsubsection{Bedroom}

Being the main function space for people to rest, the decoration of the bedroom directly affect people's lives, work and study. As the growth of the age, the elderly health gradually decays, making them spend more time resting in the bedroom than the young.

1. Good natural lighting and ventilation

As the main space of the elderly to rest, $\mathrm{T}$ 、 the bedroom should have a good natural lighting and ventilation. For action inconvenience, long-term bedridden elderly, bedroom is the main space of life. Good natural lighting and ventilation can improve the environmental comfort of the bedroom. It is not only beneficial to the bedroom and humidity regulation of indoor air quality, but also can eliminate the peculiar smell of the interior. Medical research has shown that enough sunshine has the disinfection effect on the room. It can purify indoor air, and also improve the quality of living environment.

2. Reasonable space scale

The spatial scale of the bedroom should consider the size of the furniture such as beds, TV arks, storages and the passage width of the elderly. As the main furniture bed affects the layout of the bedroom. To make it convenient for the elderly to climb from either side, the bed should decorate a position against the wall in the center of the bedroom. To sum up, the width of the bedroom should be greater than $3600 \mathrm{~mm}$, and its size should be reasonable according to the number of users and function, but should not be less than $3600 \mathrm{~mm}$.

3. Good sound insulation performance

If in the noise environment of certain intensity, the elderly cause further psychological irritable mood than other age groups of people. As the rest space for the elderly, the bedroom should enhance the sound insulation ability of partition wall, doors and Windows, and keep away from the elevator shaft

\subsubsection{Bathroom}

As the most secret place in the home, the bathroom is an activity space of defecation, wash, bath, a space of most frequently used, most prone to fall and hurt. So we should pay attention to the design of toilet security and accessibility

1. Reasonable space scale

The scale of the bathroom for the old people should be moderate. On the one hand, the scale will result in sanitary ware arrangement, not only use inconveniently, but also widened the action route, thus increase the risk of accidents. On the other hand, too small a scale will make the elderly inflexible in activities, resulting in collision with sanitary ware, and also increase the risk of accidents. What's more, small scale will make it difficult for wheelchair to enter or wiggle, which is inconvenience. In some western countries, they require $10 \%$ of the elderly housing residential unit be equipped with bathroom for wheelchair users. 


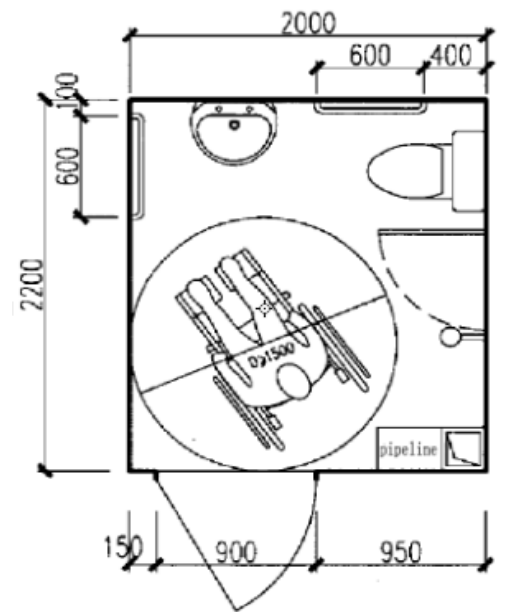

Fig. 1 Reasonable space scale

\section{Reasonable functional division}

The most cause of the accident in toilet is slippage, so toilet ground should take slippery measure, and it is also necessary to divide into wet and dry area. In the bathroom, we usually put the wet area with partition form independent regional side such as shower and tub, and decorate the dry area in the door side such as toilet, wash basin.

3. Considering variability of the bathroom

As the growth of the age, old people of different ages are in different requirement of the bathroom. In order to adapt to different stages of physical condition, it should meet the requirements of variability. First partition location should be able to change, that is to say, change the partition location to divide the wet area to reduce the security hidden danger. Second, sanitary ware location should be able to change, in other words, by changing the position of sanitary ware , we can satisfy the requirement of barrier-free toilet. Finally, the door hole location and size should be able to change, that is, change the location and size to make the barrier-free facilities and the needs of the disabled come in and out.

\subsubsection{Kitchen}

Home-based care for the aged is the most basic way of pension in our country, but ordinary kitchen space own a lot of inconvenience or even dangerous for old people. So it is necessary to design high quality kitchen to improve their quality of life,. Old people can not only make up for the loss or weakening of physiological and psychological function, but also improve their ability to care for life.

1. Good natural lighting and ventilation

Because the elderly decrease senses such as vision and smell, their requirement for the light and ventilated is higher than young people. Their kitchen should have enough natural light, because the sun's color is best to facilitate the elderly to see food and dirt clearly. A large number of lampblack gases that is produced in the kitchen cooking will influence the old people's health, so it is important to pay special attention to the natural ventilation in the design of the kitchen of the elderly residential.

2. Reasonable space scale

Kitchen of the old people should have appropriate space scale to meet the process of operation so as to make the operation flow transition smooth. Work station position should first choose $U$ and $L$ layout. Considering the elderly who use the wheelchair, operation stage should be set aside $1500 \mathrm{~mm}$ activity space. To reduce the walking routes of elderly people, we introduce the dining room to the kitchen. In some western countries, they require $5 \%$ of the elderly housing residential unit be equipped with kitchen equipment, working space and storage space to let wheelchair users reach and use. 


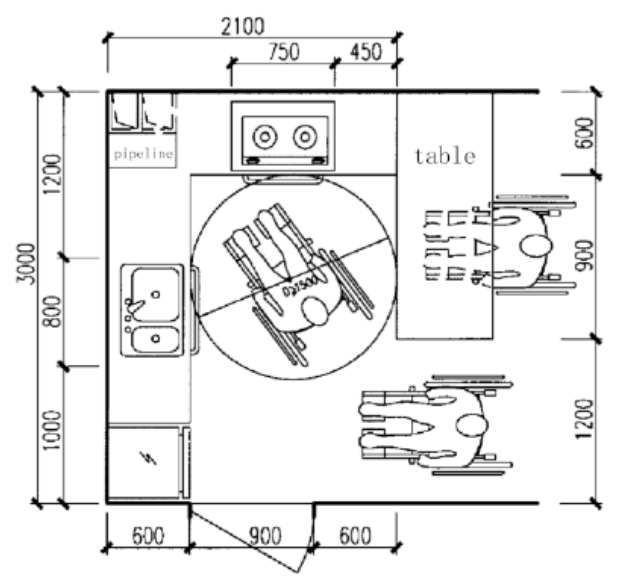

Fig. 2 Reasonable space scale

3. Choose ground material reasonably

The daily activities of older persons are in the kitchen, but the kitchen is the very place where frequent accidents occur. Therefore it is particularly important to make a reasonable choice of ground material to improve the kitchen. With the increase of age, the elderly first lose the ability to walk flexibly. So the ground material should meet the requirement of antis lip first, on the basis of which should also meet t characters of easy clean, incombustible and environmental protection.

\section{Conclusion}

With the intensification of social aging, the ageing problem gets wide attention from all walks of life. As the container of human life, residential buildings have close relationship with the life of old people. According to the "people-oriented" and the basic principles of "fully respect and care for the elderly", guarantee the basic requirement of "safe, healthy and use", improve the quality of elderly people, make the elderly residential building meet the demand of the elderly health physical changes and activity characteristics are of positive significance to social development. But at present the elderly residential building design theoretical system has not been formed, thus there are still so many things that are needed to complete, which in turn requires architects design personalized and elaborately by processing further study of the psychological, physiological characteristics and needs of old people, as well as giving full consideration to the elderly living habits. Let us make a positive contribution for the special populations together.

\section{References}

[1] Eckhard Feddersen.etc, Global Elderly Residential Building Design Manual, 2011, translated by Sun Hai xia.

[2] (the U.S) Reznikooff.s.c and so on, Standard Atlas of Interior Design[M], 1997, china building industry press, translated by Zhang Da yu.etc.

[3] Wu Yu shao, Old Blue Book: China Aging Development Report（2013）, 2013, Social Sciences Academic Press.

[4] the State Council, the State Council on the 12th Five-year Plan Issued By the China Aging Development of Notice, 2011.

[5]China National Bureau of Statistics, China Statistical Yearbook, 2014.

[6] China academy of building standard design, 04J923-1Residential Building for the Aged, 2004. 
[7] Industry standard of the People's Republic of China, The old building design specificationJGJ122-99, 1999, china building industry press.

[8] The national standard of the People's Republic of China. The elderly residential building design standardGB/T50340-2003, 2003, China building industry press. 